\title{
APRENDIZAGEM SIGNIFICATIVA CONCEITUAL, PROCEDIMENTAL E ATITUDINAL: Uma Releitura da Teoria Ausubeliana
}

\author{
Fernanda Frasson ${ }^{1}$ \\ Carlos Eduardo Laburú ${ }^{2}$ \\ Andréia de Freitas Zompero ${ }^{3}$
}

\begin{abstract}
RESUMO
Este estudo teórico faz uma releitura da Teoria da Aprendizagem Significativa de modo a compô-la com o modelo teórico dos Conteúdos de Aprendizagem Conceitual, Procedimental e Atitudinal. O objetivo é avançar na proposta de integração entre tais eixos teóricos, tendo em vista a necessidade de uma atuação escolar que favoreça a formação acadêmica de competências procedimentais e atitudinais, além das conceituais, nos aprendizes. Segundo nossa análise, os pressupostos da Teoria da Aprendizagem Significativa podem ser extrapolados para mais de um ensino que privilegie a aprendizagem conceitual. Sob esse viés, a aprendizagem significativa de conceitos, procedimentos e atitudes deve ser complementar, o que permite ao aprendiz a compreensão global do ensinado. Com as elaborações teóricas postas, pretende-se colaborar para avançar as reflexões da área de ensino e aprendizagem, ao mesmo tempo que se faz reconhecer um campo de estudos tendo como base os referenciais teóricos abordados.
\end{abstract}

Palavras-chave: Teoria da aprendizagem significativa. Aprendizagem significativa conceitual. Aprendizagem significativa procedimental. Aprendizagem significativa atitudinal.

\section{CONCEPTUAL, PROCEDURAL AND ATTITUDINAL SIGNIFICANT LEARNING:} A RE-READING OF THE AUSUBELIAN THEORY

\section{ABSTRACT}

This theoretical study re-reads the Significant Learning Theory in order to compose it with the theoretical model of conceptual, procedural and attitudinal Learning Contents. The objective is to advance in the proposal of integration between these theoretical axes, considering the need of a school performance that favors the academic formation of procedural and attitudinal competences, besides the conceptual, in the apprentices. According to our analysis, the assumptions of Significant Learning Theory can be extrapolated to more than one teaching that privileges conceptual learning. Under this bias, meaningful learning of concepts, procedures and attitudes must be complementar, which allows the learner to comprehend the overall teaching. With the theoretical elaborations put forward, we intend to cooperate to advance the reflections of the area of teaching and learning, while a field of studies based on the theoretical references discussed becomes recognized.

Keywords: Significant learning theory. Conceptual significant learning. Procedural significant learning. Attitudinal significant learning.

RECEBIDO EM: 7/3/2019

ACEITO EM: 9/5/2019

\footnotetext{
${ }^{1}$ Doutoranda em Ensino de Ciências pela Universidade Estadual de Londrina (UEL). Bolsista Capes. ferfrasson@hotmail.com

2 Doutor em Educação pela Universidade de São Paulo. Docente associado do Departamento de Física e do Programa de Pós-Graduação em Ensino de Ciências da Universidade Estadual de Londrina (UEL). É bolsista pelo CNPq-Brasil (processo 302281/2015-0). laburu@uel.br

${ }^{3}$ Pós-doutora em Ensino de Ciências pela Universidade Estadual de Londrina (UEL), tendo realizado parte dos estudos na Universidade do Minho, em Portugal. Docente do Departamento de Biologia da UEL e do Programa de Pós-Graduação em Ensino de Linguagens e Tecnologias na Universidade Norte do Paraná (Unopar). andreia.zompero@unopar.br
} 
Documentos oficiais de ensino têm estabelecido e orientado que as abordagens educativas, nas escolas brasileiras, devem concorrer para assegurar aos estudantes o desenvolvimento de competências para suas formações humanas integrais, visando à necessidade e ao interesse na construção de uma sociedade mais justa, democrática e inclusiva (BRASIL, 1996, 2013, 2017). No sentido pretendido por esses textos, "competência é a mobilização de conhecimentos (conceitos e procedimentos), habilidades (práticas, cognitivas e socioemocionais), atitudes e valores para resolver demandas complexas da vida cotidiana, do pleno exercício da cidadania e do mundo do trabalho" (BRASIL, 2017, p. 8).

A instituição dessa cultura da aprendizagem em sala de aula, contudo, ainda não se concretizou (RAMAL, 2017), dada a incompatibilidade com os formatos escolares frequentemente dominantes, que se mantêm conteudistas diante das realidades postas. Insuficiência de tempo para cumprir todos os tópicos curriculares, quantidade excessiva e diversidade de alunos em sala de aula, dificuldades em encontrar desafios adequados para as necessidades dos aprendizes e imperativo de avaliações somativas são algumas das barreiras encontradas para a efetivação de um ensino que privilegie o desenvolvimento das competências mencionadas (SANTOS, 2016).

Diante desse cenário, temos nos interessado por realizar reflexões a respeito dos referenciais teóricos que abordam a temática do desenvolvimento de competências conceituais, procedimentais e atitudinais em aprendizes e que, de fato, ofereçam disposições sobre a prática de um ensino que favoreça a aprendizagem significativa de tais conteúdos em sala de aula. Pozo (1998) e Moreira (2012) já esboçaram que a abrangência da aprendizagem significativa está para além de conteúdos conceituais. Sob essa perspectiva, nosso objetivo neste estudo é avançar na análise das conexões entre a Teoria da Aprendizagem Significativa (AUSUBEL, 1963, 2000; MOREIRA; MASINI, 1982; MOREIRA, 2006) e o modelo teórico dos Conteúdos de Aprendizagem Conceitual, Procedimental e Atitudinal, de Coll et al. (1998), Zabala (1998) e Pozo e Gómez Crespo (2009).

\section{A TEORIA DA APRENDIZAGEM SIGNIFICATIVA}

A Teoria da Aprendizagem Significativa foi elaborada por David Ausubel na década de 60 do século 20 (AUSUBEL, 1963). Conceitualmente, a aprendizagem significativa é o processo pelo qual uma informação nova associa-se a uma outra especificamente relevante já existente na estrutura de conhecimento do indivíduo. Esse processo envolve a interação da nova informação com um conceito subsunçor, ou simplesmente subsunçor (AUSUBEL, 1963), pertencente à estrutura cognitiva do indivíduo (MOREIRA, 2014).

Segundo Ausubel (1963), para que a aprendizagem seja significativa uma nova informação precisa se ancorar de maneira substantiva, e não arbitrária, no que o aprendiz já sabe. ${ }^{4} \mathrm{O}$ termo substantiva deve ser entendido como não literal, não ao pé da letra,

\footnotetext{
${ }^{4}$ Cabe esclarecer aqui que nem sempre o subsunçor é um conhecimento aceito como correto pela comunidade científica. O subsunçor pode ser uma concepção de senso comum que o indivíduo utiliza para estabelecer regularidades do mundo, tornando-o mais previsível e controlável. As concepções de senso comum podem ser aprendidas pelos indivíduos a partir de suas percepções do mundo, culturalmente ou, ainda, na escola (quando a exposição do conteúdo é feita de maneira deformada ou simplificada demais pelo professor ou material didático). Discussões sobre mobilização cognitiva para mudanças nas concepções de senso comum são feitas por vários pesquisadores, contudo não trataremos delas aqui. Neste artigo, idealizamos que a aprendizagem significativa aconteça a partir da ancoragem de novos conhecimentos a subsunçores consentidos cientificamente.
} 
de forma que faça sentido para o aprendiz. A expressão não arbitrário manifesta que a interação não é com qualquer ideia prévia, mas sim com um conhecimento considerado importante pelo aluno, já existente em sua estrutura cognitiva. Seja por recepção ou por descobrimento, a atribuição de significados a novos conhecimentos depende da existência de conhecimentos prévios do aprendiz, e da interação com eles. ${ }^{5} \mathrm{~A}$ figura a seguir é um esquema, elaborado por Moreira (2011), que expressa como Ausubel imaginou a interação entre conhecimento prévio e novo.

Figura 1 - A assimilação ausubeliana

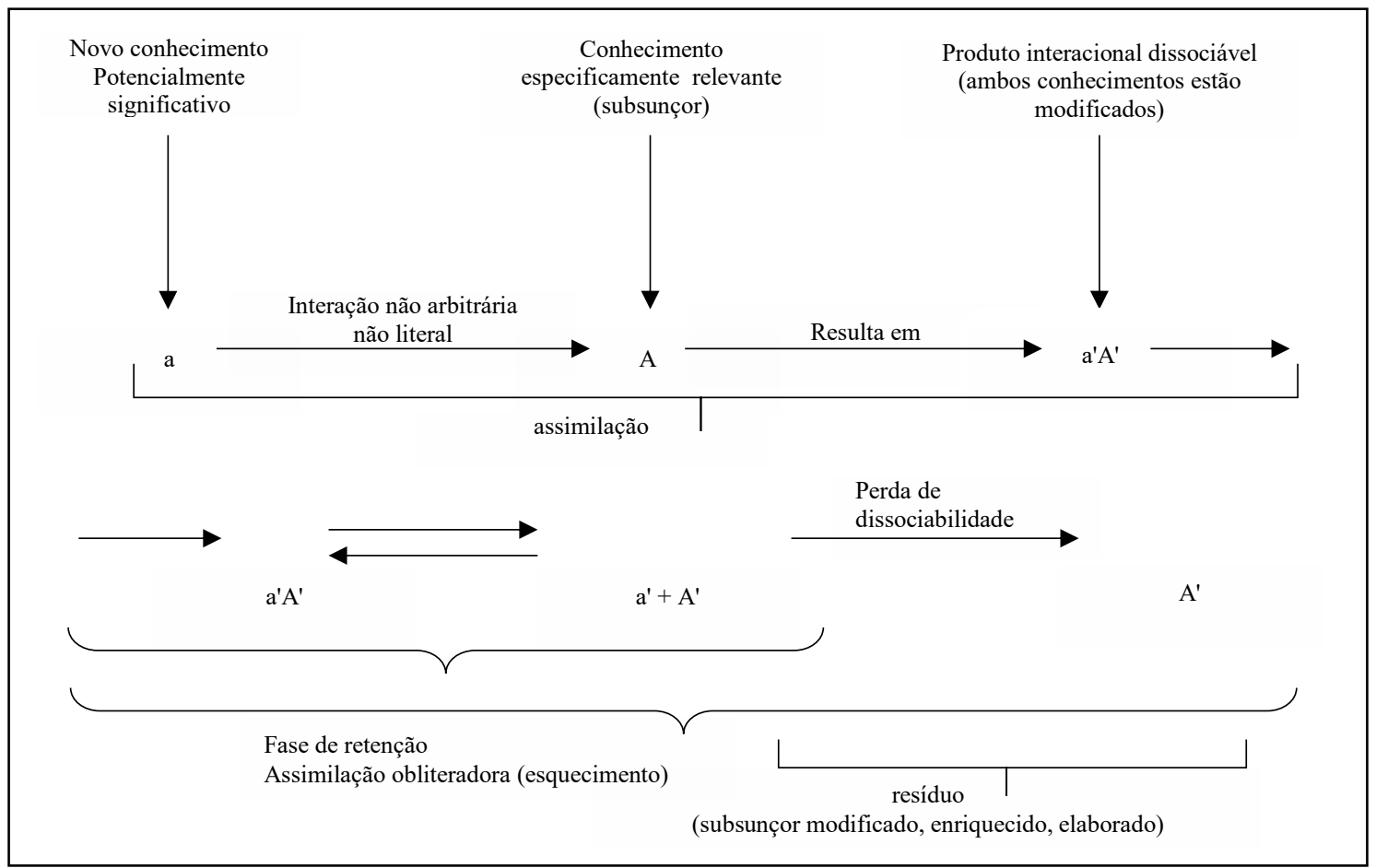

Fonte: MOREIRA (2011, p. 158).

Segundo o esquema apresentado na Figura 1, Ausubel idealizou que a interação entre um conhecimento potencialmente significativo (a) e o subsunçor ( $A$ ) ocorre na fase denominada assimilação e gera, incialmente, um produto dissociável, porém tanto o novo conhecimento quanto o subsunçor passam a apresentar sinais um do outro ( $\left.a^{\prime} A^{\prime}\right)$. À medida que ocorre a exposição ao novo conhecimento, a assimilação possibilita que o conhecimento prévio seja modificado, enriquecido e elaborado, de forma que não se percebe mais a dissociabilidade entre o saber novo e o prévio $\left(A^{\prime}\right)$; este passa a ter, então, o estatuto de novo subsunçor.

Ausubel concebe que o armazenamento de informações no cérebro humano é organizado em forma de uma hierarquia conceitual, na qual elementos mais específicos de conhecimento são ligados a conceitos mais gerais, mais inclusivos. Estrutura cognitiva

\footnotetext{
${ }^{5}$ Em 1978, Ausubel, Novak e Hanesian (1978) ampliaram a discussão acerca da Teoria da Aprendizagem Significativa e afirmaram que para ela acontecer o material a ser aprendido e o aprendiz precisam cumprir certas condições. Consideramos apropriado discorrer sobre tais condições mais à frente, no tópico Aprendizagem Significativa Conceitual deste texto.
} 
significa, nesse contexto, uma estrutura hierárquica de conceitos (AUSUBEL, 2003). A Figura 2 traz um diagrama, elaborado por Moreira (2011), de como Ausubel imagina que aconteça a organização do conhecimento na estrutura cognitiva dos seres humanos.

Figura 2 - Organização hierárquica de conceitos na estrutura cognitiva

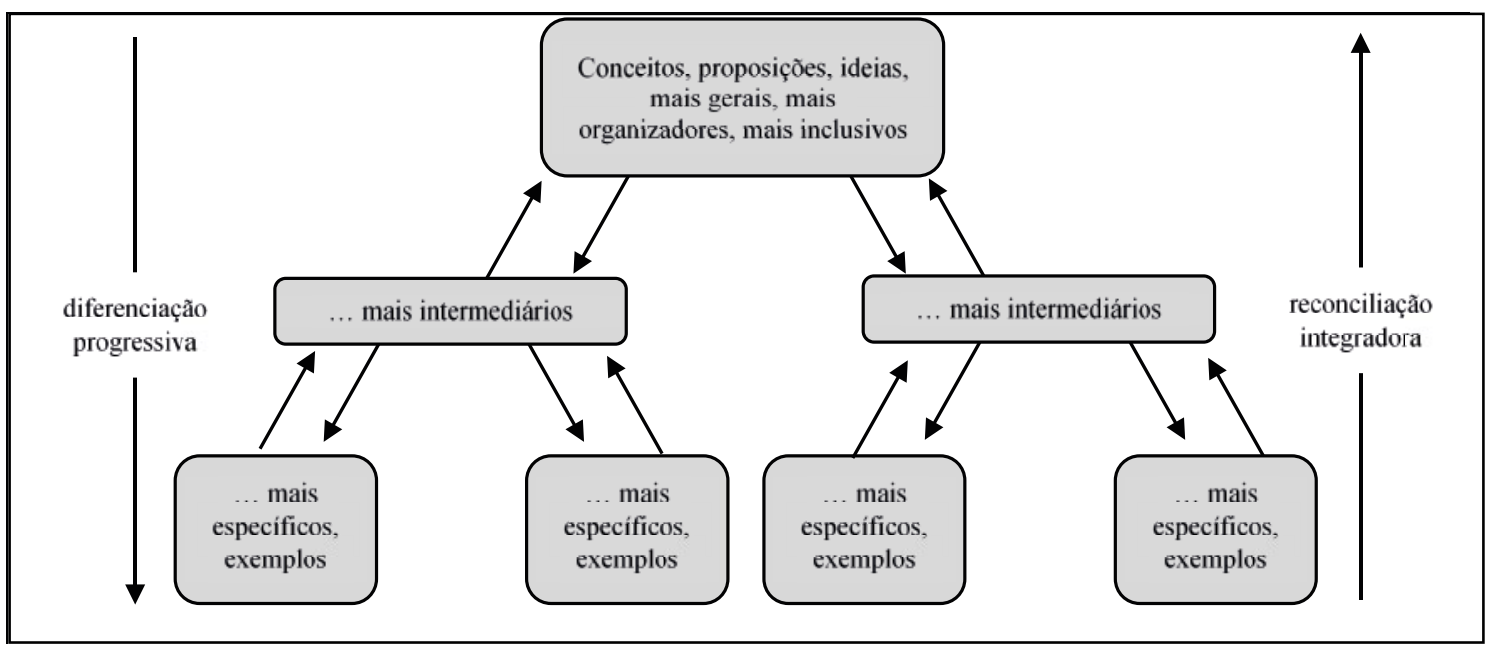

Fonte: MOREIRA (2011, p. 44).

A Figura 2 permite inferir que, independentemente de o conhecimento prévio ser mais inclusivo ou mais específico, conforme a aprendizagem significativa ocorre, ele é desenvolvido, elaborado e diferenciado por conta das sucessivas interações pelas quais passa com os novos conhecimentos, por isso a estrutura cognitiva é dinâmica e os conceitos mais específicos podem se tornar inclusivos em outras situações de aprendizagem. Moreira (2012) afirma que, quanto mais interações ocorrem entre conhecimentos prévios e conhecimentos novos, mais estáveis se tornam os saberes na estrutura cognitiva dos indivíduos.

Apesar de nos escritos de Ausubel encontrarmos que o subsunçor é um conceito, uma ideia ou uma proposição já existente na estrutura cognitiva do indivíduo, Pozo (1998) defende que, além de fatos e conceitos, considerar os conhecimentos atitudinais e procedimentais que o aluno já possui é essencial para a promoção da aprendizagem que leva à formação integral de um indivíduo. Em consonância com Pozo (1998), Moreira (2012) observa que, atualmente, considerar apenas os conhecimentos declarativos (conceituais) como subsunçores não parece mais adequado, pois restringe muito o significado de conhecimento prévio, induzindo ao pensamento de que ele seja relacionado apenas a conceitos. Nesse sentido, é preciso considerar o subsunçor como um conhecimento prévio especificamente importante para uma nova aprendizagem, destacando-se que tal conhecimento pode ser igualmente procedimental ou atitudinal, complementando o conceitual.

\section{OS CONTEÚDOS DE APRENDIZAGEM}

Como indicado anteriormente, os conhecimentos presentes na estrutura cognitiva dos indivíduos podem possuir natureza conceitual, procedimental e atitudinal. Aparentemente essa classificação é simples, no entanto carrega grande força pedagógica, 
pois diferencia os conhecimentos em conteúdos de aprendizagem, segundo o uso que deles se deve fazer. Assim, há conteúdos que é preciso "saber" (conceituais), conteúdos que é necessário "saber fazer" (procedimentais) e conteúdos que formam o "ser" (atitudinais) (ZABALA, 1999).

Entendemos que a formação de competências nos alunos será mais bem-sucedida se as diferentes naturezas dos conteúdos forem lecionadas de forma complementar e concomitante, pois dessa forma os aprendizes tornam-se aptos a relacionar os conhecimentos científicos ao uso social dos saberes escolares.

A classificação triádica dos conteúdos de aprendizagem foi descrita por Coll (1986) e desde então foi desenvolvida por vários pensadores da área, entre eles Coll et al. (1998), Zabala (1998) e Pozo e Gómez Crespo (2009). O quadro a seguir mostra como esses pesquisadores consideram a composição dos conteúdos curriculares.

Quadro 1 - Composição dos conteúdos no currículo

\begin{tabular}{|l|c|c|c|}
\hline Tipos de conteúdos & Mais específicos & $\leftrightarrow$ & Mais gerais \\
\hline Conceituais & Fatos/Dados & Conceitos & Princípios \\
\hline Procedimentais & Técnicas & & Estratégias \\
\hline Atitudinais & Atitudes & Normas & Valores \\
\hline
\end{tabular}

Fonte: POZO; GÓMEZ CRESPO (2009, p. 28).

De acordo com o descrito por Pozo e Gómez Crespo (2009) no Quadro 1, os conteúdos conceituais são constituídos por fatos e/ou dados, conceitos e princípios; os procedimentais, por técnicas e estratégias; e os atitudinais, por atitudes, normas e valores. Grosso modo, a aprendizagem dos constituintes específicos de cada conteúdo (fatos/ dados, técnicas e atitudes) deve ser o passo inicial no percurso que leva à aprendizagem dos constituintes intermediários (conceitos e normas) e gerais (princípios, estratégias e valores). Na sequência, discorreremos com mais detalhes sobre a composição de cada conteúdo curricular (POZO; GÓMEZ CRESPO, 2009).

\section{Conteúdo Conceitual}

Fatos, conceitos e princípios são consubstanciais, pois têm naturezas declarativas ou verbais. Zabala (1998) os diferencia descrevendo que: os factuais são fatos, acontecimentos, situações, dados e fenômenos concretos e singulares/pontuais. Exemplos deles seriam a idade de uma pessoa, a data da conquista de um território, a localização ou altura de uma montanha, os nomes, os códigos, os axiomas, etc. Os conceitos são acepções de fatos, objetos ou símbolos que têm características comuns. Como exemplos temos saber o que é mamífero, densidade, impressionismo, função, sujeito, romantismo, demografia, nepotismo, cidade, potência, concerto, cambalhota, etc. Os princípios são inferências sobre os fatos, objetos ou situações em relação a outros fatos, objetos ou situações, que normalmente constituem relações de causa-efeito ou de correlação. Por exemplo, leis ou regras que relacionam demografia e território, normas de uma corrente arquitetônica ou literária, conexões que se estabelecem entre diferentes axiomas matemáticos, etc. 
Ante essas definições, conhecer um dado ou um fato é diferente de dar-lhes significados. Os dados precisam ser relacionados numa rede de significados que explique por que eles ocorrem e que consequências têm; essa rede de significados é descrita nas formas de conceitos e proposições conceituais. Os princípios são a coordenação de conceitos estruturais gerais resultantes da superordenação na organização conceitual de uma área (POZO; GÓMEZ CRESPO, 2009).

\section{Conteúdo Procedimental}

Conceitos, procedimentos e atitudes pertencem a naturezas cognitivas distintas dado o pluralismo multifuncional da mente (LABURÚ; ZOMPERO; BARROS, 2003), isso sem dizer dos perfis intelectuais múltiplos dos indivíduos com desempenhos desiguais (GARDNER, 1995). Os conteúdos procedimentais têm natureza prática por excelência e precisam ser ensinados de maneiras distintas dos demais. Segundo Coll e Valls (1998, p. 77), procedimentos são "ações ordenadas, orientadas para a consecução de uma meta".

Apesar de no cotidiano escolar entender-se mais que o conteúdo procedimental está relacionado, apenas, às habilidades técnicas (técnicas de medição, leitura e operacionalização de aparelhos, realização de manipulações práticas em geral e desenvolvimento de destrezas para sua realização), ele admite também as estratégias de raciocínio e aprendizagem. Enquanto a técnica é uma rotina automatizada devido à prática repetida, as estratégias envolvem planejamento e escolha das técnicas a serem empregadas diante das situações do dia a dia. Para Pozo e Gómez Crespo (2009), técnicas e estratégias são complementares, pois o uso eficaz de uma estratégia depende, em grande medida, do domínio das técnicas que dela fazem parte.

Zabala (1999) amplia a discussão sobre a caracterização dos conteúdos procedimentais e defende que um procedimento pode ser de essência motora (saltar, perfurar, recortar, etc.) ou cognitiva (inferir, ler, traduzir, etc.); pode depender de poucas ações (perfurar, calcular, traduzir, etc.) ou de muitas ações (observar, ler, desenhar, etc.); pode precisar de uma sequência de ações exatas/algorítmicas (abotoar, somar, procurar uma palavra no dicionário, etc.) ou não, sendo considerado heurístico (classificar, ler, aprender, etc.). Segundo o autor, todo conteúdo procedimental é enquadrado em, pelo menos, uma dessas caracterizações.

\section{Conteúdo Atitudinal}

$\mathrm{Na}$ atual conjuntura escolar, conteúdos atitudinais são, possivelmente, os mais complexos de serem abordados, tendo em vista ser a escola um ambiente formado por indivíduos provenientes de diferentes culturas. A função social que a formação atitudinal ocupa, contudo, torna necessária sua presença no ambiente escolar. Discussões envolvendo tal temática consideram que as atuações dos indivíduos são resultantes da obediência deles às normas estabelecidas pelo grupo social no qual estão inseridos ou das reflexões e interiorizações particulares, que levam à formação de valores pessoais.

Sarabia (1998, p. 122) define atitudes, valores e normas. Os primeiros referem-se às "tendências ou disposições adquiridas e relativamente duradouras a avaliar de um modo determinado um objeto, pessoa, acontecimento ou situação e a atuar de acordo com essa 
avaliação". Os segundos referem-se a "princípios éticos com respeito aos quais as pessoas sentem um forte compromisso emocional e que empregam para julgar condutas" (SARABIA, 1998, p. 127). Os últimos aludem a "padrões de conduta compartilhados pelos membros de um grupo social" (p. 128). Essas definições consideram que os comportamentos têm três componentes básicos: o cognitivo (conhecimentos), o afetivo (sentimentos e preferências) e o condutual (ações manifestas e declarações de intenção) (ZABALA, 1998).

Ante essas definições, podemos depreender que, para os alunos compreenderem um conteúdo atitudinal aproximando-o do conhecimento científico de forma a mudarem suas atitudes e construírem comportamentos com consistência, ${ }^{6}$ fruto da reflexão sobre normas e valores, os professores, mais do que discursos éticos, devem utilizar estratégias que levem a reflexões e elaborações complexas de caráter pessoal (EL-HANI; MORTIMER, 2007; POZO; GOMÉZ CRESPO, 2009).

\section{CONEXÕES ENTRE TEORIA DA APRENDIZAGEM SIGNIFICATIVA E CONTEÚDOS DE APRENDIZAGEM}

A defesa por uma abordagem escolar que proporcione a aprendizagem de conceitos, procedimentos e atitudes de forma congregada e significativa também é levantada e discutida por Melendéz (2012), Nardy e Laburú (2014) e Frasson (2016). A ocupação central desses trabalhos é a discussão sobre a construção cognitiva de conceitos ser profunda e expressiva, a aprendizagem de procedimentos levar a ações conscientes sobre o mundo e a formação de valores e comportamentos ser consistente. Para que este tipo de aprendizagem ocorra é necessário efetivar um programa de ensino pautado em teorias que considerem as diferentes naturezas dos conteúdos e o aprender significativamente. Diante disso, a seguir explanaremos as conexões que vislumbramos entre a Teoria da Aprendizagem Significativa e o modelo teórico dos Conteúdos de Aprendizagem. Mesmo não sendo o mote de nosso trabalho, no decorrer da explanação relacionamos algumas estratégias educacionais que podem subsidiar um ensino que contemple os eixos teóricos aqui apresentados, pois entendemos que tal inserção enriquece a releitura teórica que estamos fazendo.

\section{Aprendizagem Significativa Conceitual ${ }^{7}$}

Segundo Zabala (1998) e Pozo e Gómez Crespo (2009), uma pessoa aprende um conceito quando consegue dar-Ihe significado. Dar-lhe significado seria equivalente a traduzi-lo com suas próprias palavras ou parafraseá-lo (PERUCCI, 2015; HERNANDES, 2018). O aprendizado de um conceito torna o aprendiz capaz de usá-lo na interpretação, na compreensão e na exposição de outros fenômenos ou situações. Ausubel, Novak e Hanesian (1978) afirmam que para a aprendizagem significativa de conceitos acontecer o material e o aprendiz precisam cumprir certas condições, conforme Figura 3.

\footnotetext{
O termo consistência está relacionado à tendência das pessoas em organizar as suas atitudes em estruturas internas consistentes, o que as tornariam mais duradouras e concretas (SARABIA, 1998). É a esse aspecto atitudinal que o texto que estamos apresentando se refere.

Apesar de conceitos, procedimentos e atitudes formarem um corpo integrado de conhecimentos necessários à formação do estudante, na prática os diferenciamos por questões didáticas.
} 
Figura 3 - Condições para a aprendizagem significativa conceitual

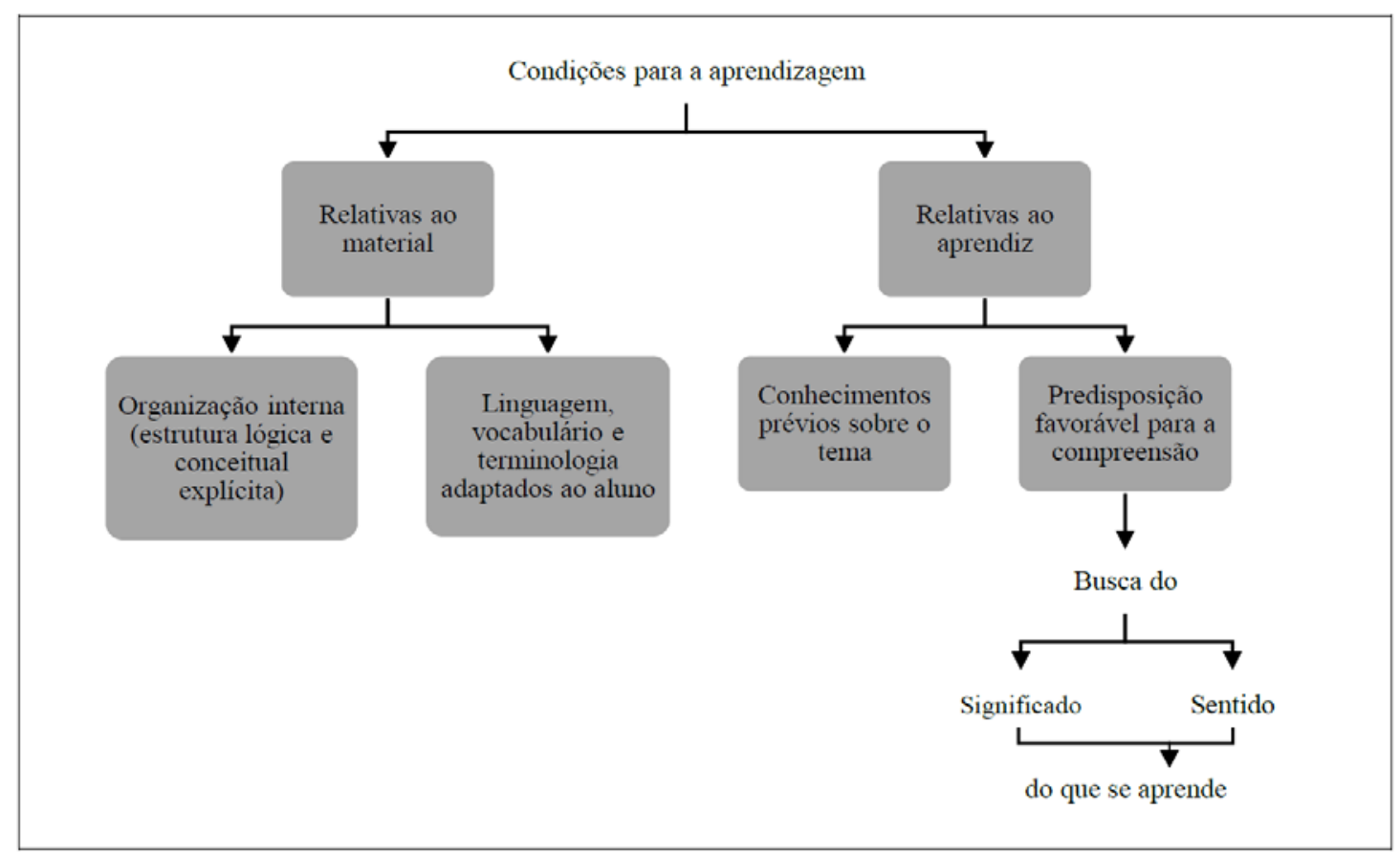

Fonte: Adaptado de POZO; GÓMEZ CRESPO (2009, p. 85).

De acordo com a Figura 3, a aprendizagem significativa de conceitos depende de o material de ensino possuir organização interna (estrutura lógica e conceitual) e linguagens, vocabulários e terminologias adaptadas aos alunos. Em relação ao aprendiz, ele deve ter subsunçores sobre o tema e estar predisposto a aprender. Sobre a organização do material, Ausubel, Novak e Hanesian (1978) salientam que ele deve estar disposto sequencialmente, aproveitando-se das dependências hierárquicas naturais que possui dentro de uma rede conceitual. Com relação ao uso de material com linguagens adaptadas aos estudantes, Laburú e Silva (2011) contribuem argumentando que, além da linguagem verbal, a gráfica, a diagramática, a experimental, a tridimensional e a figurativa, entre outras, devem ser empregadas em situações de ensino e aprendizagem, tendo em vista que, ao utilizar os multimodos de representar um mesmo conceito, aumenta-se o potencial de aproximação que este conceito pode ter junto a estrutura cognitiva do aprendiz, pois proporciona o aproveitamento das dimensões psicológicas e os estilos subjetivos de aprendizagem de cada estudante.

Como referido anteriormente, Ausubel (1963) defende que um novo conhecimento precisa ser ancorado em um conhecimento prévio para que a aprendizagem seja significativa; diante disso temos que, durante o ensino, o professor deve introduzir uma nova matéria apenas depois de se certificar que os alunos dominam os conhecimentos prévios necessários à nova aprendizagem. A despeito da predisposição do aprendiz para aprender, Claxton (1984), Alonso Tapia (1997), Huertas (1997), Pozo e Gómez Crespo (2009), entre outros, têm discutido a necessidade de uma reavaliação da organização das atividades e dos currículos escolares para que estes considerem os centros de interesse dos aprendizes e a promoção do trabalho cooperativo que permita o desenvolvimento da autonomia dos alunos. Esse tipo de abordagem deve levar os envolvidos no processo educativo a pensar que a motivação intrínseca do aluno está diretamente relacionada à interação social na sala de aula. 
Partindo dessas condições, vislumbramos a compatibilidade entre um ensino que tem por objetivo a aprendizagem de Conteúdos Conceituais e a Teoria da Aprendizagem Significativa, pois, para que o estudante aprenda significativamente conceitos, deve perceber a alocação do novo conceito, que lhe está sendo apresentado, à rede de conceitos que já está presente em sua estrutura cognitiva e que deveria considerar substantiva, e não arbitrária. Essa percepção é facilitada quando o material de ensino apresentado possui organização interna, de forma que as novas informações tenham conexão lógica e conceitual com outras informações, que já estejam presentes na estrutura cognitiva do aprendiz. $\mathrm{O}$ uso de múltiplas formas de representar um conceito também auxilia o estudante na percepção das ancoragens que estamos sugerindo. Conhecer os subsunçores do aprendiz, nesse processo, é fundamental, pois permite ao professor enfatizar, nas suas práticas de ensino, as correlações conceituais entre o conhecimento novo e o prévio.

Pozo (1998) sugere dois tipos de atividades para o ensino que proporcionam a aprendizagem significativa de conceitos: atividades de descobrimento e atividades de exposição. A aprendizagem por descobrimento ${ }^{8}$ ou pesquisa consiste em apresentar aos alunos uma tarefa e um material de trabalho para que eles mesmos, por meio da observação, análise e pesquisa, descubram os conceitos e as relações conceituais necessárias para a realização da tarefa. Esse tipo de trabalho promove uma forte atividade mental e permite a construção de significado e funcionalidade dos novos conceitos; são atividades que favorecem a compreensão do conceito para utilizá-lo na interpretação ou no conhecimento de situações ou na construção de outras ideias (ZABALA, 1998).

A aprendizagem por exposição fundamenta-se na recepção da informação conceitual que se deve adquirir. Dessa forma, os conteúdos não precisam ser descobertos, mas sim assimilados significativamente, a partir da sua relação deles conhecimentos anteriores (POZO, 1998). É justamente a percepção da relação dos conhecimentos novos com a rede de significados já presentes na estrutura cognitiva do aprendiz e por ele estimada, que diferencia a aprendizagem significativa da aprendizagem mecânica. Apesar de se tratar de propostas de ensino extremas em suas maneiras de organizar as atividades didáticas, hoje se assume a conveniência de buscar a complementaridade de ambas, ou seja, é preciso pensar e analisar em quais casos as atividades de descobrimento e de exposição se tornam significativas para os alunos em situações de apropriação conceitual.

\section{Aprendizagem Significativa Procedimental}

Em relação à aprendizagem de procedimentos, temos que seu principal objetivo é a aprendizagem dos estudantes de maneira compreensiva, profunda, funcional e permanente, atribuindo-Ihes significado elaborado (COLL; VALLS, 1998). Para que sobrevenha esse tipo de aprendizagem, Pozo e Gómez Crespo (2009) descreveram que o ensino deve seguir quatro fases de instrução. Apresentamos tais fases no Quadro 2.

\footnotetext{
${ }^{8}$ Laburú e Carvalho (2005) trazem à tona que esse tipo de aprendizagem tem sido alvo de críticas, dada sua concepção empirista da aprendizagem. Nesse sentido, quando do desenvolvimento de atividades que proporcionem a aprendizagem por descoberta, os professores devem estar atentos aos resultados alcançados pelos estudantes diante das atividades de pesquisa, análise e observação para orientar os casos de desajustes com a aprendizagem de saberes científicos.
} 
Quadro 2 - Fases da aprendizagem significativa procedimental

\begin{tabular}{|l|l|l|}
\hline Instrução & \multicolumn{1}{|c|}{ Fase } & \multicolumn{1}{c|}{ Consiste em: } \\
\hline Técnica & $\begin{array}{l}\text { Declarativa ou de } \\
\text { instrução }\end{array}$ & $\begin{array}{l}\text { Proporcionar instruções detalhadas da sequência de } \\
\text { ações que deve ser realizada }\end{array}$ \\
\cline { 2 - 3 } & $\begin{array}{l}\text { Automatização ou } \\
\text { consolidação }\end{array}$ & $\begin{array}{l}\text { Proporcionar a prática repetitiva necessária para auto- } \\
\text { matizar a sequência de ações a se realizar, supervisio- } \\
\text { nando sua execução }\end{array}$ \\
\hline Estratégica & $\begin{array}{l}\text { Generalização ou } \\
\text { transferência do } \\
\text { conhecimento }\end{array}$ & $\begin{array}{l}\text { Colocar situações de enfrentamento cada vez mais } \\
\text { novas e abertas, de maneira a obrigar a tomada de } \\
\text { decisões }\end{array}$ \\
\cline { 2 - 3 } & $\begin{array}{l}\text { Transferência do } \\
\text { controle }\end{array}$ & $\begin{array}{l}\text { Promover autonomia no planejamento, na supervisão } \\
\text { e na avaliação da aplicação de seus procedimentos }\end{array}$ \\
\hline
\end{tabular}

Fonte: Adaptado de POZO; GÓMEZ CRESPO (2009, p. 54).

A primeira fase, denominada Declarativa ou de Instrução, refere-se a um treinamento técnico. Inicia-se pela apresentação do professor de algumas instruções ou modelos de ação. Essas instruções devem servir para estabelecer o objetivo da atividade e especificar, com detalhes, a sequência de passos a serem realizados para atingir o objetivo/meta. Nesse momento o professor pode fazer uso de listas de instruções, apresentadas verbalmente, ou de modelos que demonstrem como executar as ações (essa exposição pode ser realizada pelo próprio professor ou demonstrada em material audiovisual).

Para que as instruções proporcionadas nesta primeira fase sejam efetivas, os professores devem estar atentos ao cumprimento de certas condições: a) as ações que constituem a sequência de ações devem ser dominadas pelos aprendizes; b) a quantidade de elementos que compõem a sequência de ações não deve ser excessiva; c) a atenção dos aprendizes deve ser dirigida às ações que são realmente relevantes para o cumprimento da meta; d) a instrução ou exposição de modelos deve ser congruente com aprendizagens anteriores (ou seja, assimilável aos programas procedimentais previamente aprendidos), fazendo com que o aprendiz reconheça, além de cada elemento individual da sequência, a lógica do programa, o que está sendo feito e por quê (POZO; GÓMEZ CRESPO, 2009).

Todas essas condições, especialmente a última, nos fazem coligar, estreitamente, a aprendizagem de procedimentos com a Teoria da Aprendizagem Significativa, pois, se cumpridas, permitirão que o aprendiz perceba a substantividade e a não arbitrariedade do que lhe está sendo ensinado, visto que a aprendizagem de novos procedimentos fica ancorada nos procedimentos prévios já aprendidos e utilizados pelo aluno.

Após a efetivação adequada da primeira fase, parte-se para a segunda, denominada Automatização ou Consolidação. Nela os alunos devem colocar em prática, repetidamente, a sequência de ações sugeridas na fase anterior, sob supervisão do professor. Aqui, a função dele não é explicar, mas supervisionar o exercício da prática, corrigindo erros e proporcionando reforços. O objetivo da fase é condensar e automatizar a sequência de ações em uma técnica ou rotina treinada (POZO; GÓMEZ CRESPO, 2009). 
Podemos coerentemente associar essa fase da aprendizagem de procedimentos à fase de assimilação proposta por Ausubel $(1963,2000)$ na Teoria da Aprendizagem Significativa. A ideia de condensar em uma forma de ação passos previamente dominados pelo aprendiz que, anteriormente, eram decompostos ou separados, remete aos potenciais de reconciliação integradora, que a assimilação de um novo conhecimento a um conhecimento prévio proporciona. Como exemplo citamos o aprender a usar um microscópio. Inicialmente aprende-se a ajustar as lentes, o feixe de luz, a lâmina a ser observada, entre outros, mas após um tempo de prática, une-se todas essas ações na técnica automatizada "observação por microscópio". Sendo assim, a organização da hierarquia cognitiva do aprendiz é revisada, modificada e enriquecida (MOREIRA, 2011).

A partir do momento em que os alunos dominam as técnicas necessárias para a realização de uma tarefa, eles podem começar a usá-las em planejamentos estratégicos. Esse é o objetivo da terceira e da quarta fases do treinamento procedimental, denominadas Generalização ou Transferência do Conhecimento e Transferência do Controle, respectivamente (POZO; GÓMEZ CRESPO, 2009). A ideia aqui é induzir os aprendizes a refletir e selecionar em seu repertório de procedimentos qual deve ser aplicado na solução de uma nova tarefa ou, ainda, na solução de uma tarefa já realizada, mas em um novo contexto. Na terceira fase, o professor deve propor as situações e esperar que o aluno resolva a partir de suas decisões, contudo ainda ajuda o aprendiz a avaliar sua conduta. Já na quarta fase o aluno autonomamente deve selecionar, realizar e avaliar a aplicação dos procedimentos que escolheu para formular sua estratégia. O objetivo de formar um aprendiz autônomo, capaz de planejar, executar e avaliar o sucesso de suas ações estratégicas é congruente com o objetivo da Aprendizagem Significativa de tornar o estudante consciente de sua aprendizagem, de forma que ele perceba o sentido e a importância do que está aprendendo (MOREIRA; MASINI, 1982; POZO, 1998; MOREIRA, 2006).

Segundo os autores, embora o cumprimento sequencial dessas quatro fases facilite a construção do saber, elas não devem ser entendidas, apenas, como fases sucessivas, pois se, em algum momento do processo de aprendizagem, o professor perceber que houve deficiência na execução ou escolha das ações pelo aprendiz, ele pode retomar a fase em questão para resolvê-la.

\section{Aprendizagem Significativa Atitudinal}

Alguns pesquisadores têm discutido o papel da educação científica na escola. Sobre isso, El-Hani e Mortimer (2007) escreveram que é atribuição dos professores de ciências estimular os alunos a entender as ideias científicas. Tal atuação, porém, deve ser culturalmente sensível, de forma que a diversidade de visões de mundo dos alunos seja levada em conta. Essa linha de pensamento é explicada em termos da defesa de uma ética de convivência para lidar com as diferenças culturais e sociais, segundo a qual o confronto de argumentos deve ocorrer para chegar à solução dos problemas científicos. Como os autores, entendemos que a abordagem dos conteúdos atitudinais na sala de aula precisa ser realizada para além da imposição de normas e valores, deve levar o aluno a reflexões pessoais sobre suas condutas, e mais, sobre como suas atitudes interferem na sociedade. 
Para que os alunos aprendam atitudes ou considerem mudar as que já mantêm, Sarabia (1998) e Pozo e Gómez Crespo (2009) afirmam que os professores podem utilizar-se de duas práticas: os reforços sociais positivo e negativo e a apresentação de modelos. O reforço social é mais indicado para os alunos das primeiras idades escolares, fase em que a criança aprende a responder a uma série de controles externos. Entre os controles que são exercidos sobre a criança para que a sua conduta se adéque às normas estão o reforço social positivo e negativo. O primeiro trata-se de ação do meio social que aumenta a possibilidade de que se produza a resposta desejada, ou seja, promove a conduta. $O$ reforço social negativo ou castigo reporta-se à ação do meio social que leva à diminuição da frequência da conduta indesejada. Esse tipo de ação não leva à aprendizagem significativa de uma atitude, pois não favorece a formação consciente e consistente de uma conduta, sendo que, provavelmente, ao serem retirados os reforços, o aprendiz passe a se comportar como lhe convier.

Sobre a aprendizagem por modelos, Sarabia (1998) destaca que um indivíduo pode formar ou mudar suas atitudes quando reflete e resolve imitar modelo(s). A imitação de um modelo é tomada pela Psicologia Social como parte de um processo de influência social. Em Moscovici, Mugny e Pérez (1991) é afirmado que o processo de influência social está relacionado à identidade das pessoas que dele participam, ou seja, a influência social ocorre quando um aprendiz quer pertencer a um determinado grupo social e, para isso, precisa se amoldar a esse grupo. O pertencimento a um grupo de referência - pessoas próximas (colegas de escola, professores, familiares, colegas da igreja, etc.), indivíduos evidenciados nos meios de comunicação (atletas, artistas, blogueiros, youtubers, etc.) ou, ainda, algum grupo fruto da imaginação - geralmente envolve, além da identificação, processos de conformismo com as normas estabelecidas pelo grupo e interiorização ou transformação de tais normas em valores pessoais. Nesse sentido, planejar a exposição do aprendiz a "modelo(s)" de condutas é um dos caminhos para levá-lo à formação e mudança atitudinal implícita que se deseja.

Pozo e Gómez Crespo (2009) ampliam a discussão sobre esse tema e acrescentam que expor um aprendiz a conflitos sociocognitivos também é uma forma de mobilizar a formação atitudinal. A introdução de conflitos ou inconsistências sociocognitivas desestabiliza as condutas e fomenta a mudança, uma vez que essas discrepâncias são, geralmente, desconfortáveis ao indivíduo quando percebidas. Citamos aqui dois tipos de conflitos sociocognitivos que podem ser introduzidos num ensino que pense na formação atitudinal e que podem promover mudança de conduta: os que se baseiam em desajustes sociais e os que provocam discrepâncias internas.

O conflito sociocognitivo baseado em desajustes sociais refere-se a levar o aprendiz a refletir sobre suas próprias condutas diante das atitudes compactuadas pelo grupo social de referência ao qual quer pertencer; isso porque as pessoas tendem a ajustar seus comportamentos aos do grupo de referência quando percebem que estão se comportando de maneira diferente dele. $O$ segundo tipo de conflito sociocognitivo surge de diferentes componentes de uma atitude (comportamentais, cognitivos e afetivos). Esse fenômeno recebe o nome de dissonância cognitiva e acontece quando um aprendiz é levado a perceber que suas condutas não condizem com as crenças ou valores que pro- 
fessa. Quando isso ocorre o aluno é induzido a refletir sobre suas ações e valores, o que pode levá-lo a mudá-los para que se estabeleça harmonia entre seus conhecimentos, valores e condutas.

Algumas técnicas que podem ser usadas para a criação de um contexto de discrepância, quando se almeja a formação e mudança atitudinal, são: a interpretação cênica; os diálogos, as discussões e os debates e as exposições em público.

A interpretação cênica refere-se à técnica de dramatização ou representação mental de diferentes papéis assumidos como próprios. Demanda que os participantes adotem de forma ativa o lugar de outra pessoa, podendo ser priorizado que se retrate o papel de alguém ou alguma situação com quem ou com que se tenha dificuldades nas suas relações pessoais. O propósito é produzir mudanças na percepção e na avaliação da outra pessoa ou situação. Pode ser feita de maneira simples, dentro da sala de aula como parte de uma aula, ou mais elaborada para apreciação de um público maior em situações mais especiais. Para que a técnica seja proveitosa o professor deve distribuir as instruções necessárias para a representação dos papéis de cada um com antecedência (SARABIA, 1998).

Os diálogos, as discussões e os debates em sala de aula podem suscitar nos alunos, após o estudo ativo de um tema, a elaboração de seus próprios argumentos e a exposição de suas atitudes a favor de um objeto, pessoa ou situação reais ou contra eles. Partir da realidade e valer-se dos conflitos que nela se apresentam, principalmente os vivenciados pelos estudantes, é fundamental para a eficácia desse tipo de atividade. A elaboração pessoal e subjetiva de argumentos dentro das circunstâncias da sala de aula - onde o sucesso pessoal e as relações afetivas exercem um importante papel - possui uma maior força na mudança atitudinal de um indivíduo do que a leitura de um texto, pois envolve reflexão (SARABIA, 1998; ZABALA, 1998). Sobre a relevância de se escolher uma representação semiótica adequada entre várias possibilidades (verbal, oral ou textual, diagramática, experimental, figurativa, algébrica, cinestésica, etc), Klein e Laburú (2012) afirmam que cada modo tem o potencial de explorar melhor a significação de determinados conteúdos.

As exposições em público exigem do aluno uma apresentação diante de pessoas que são importantes para ele. Expor um tema na aula, diante dos colegas e do professor, pode fazer com que o estudante se sinta mais atraído na situação do que quando o escuta para descrevê-lo em uma atividade escrita, podendo inclusive desenvolver um interesse pelo assunto que antes não possuía. Em um estágio mais avançado, quando o aluno se envolve a ponto de realizar uma reflexão crítica do tema, pode não só fazer uma avaliação dele, mas também das atitudes que possui em relação a ele (SARABIA, 1998; ZABALA, 1998).

Diante do exposto, estabelecemos relações entre a Teoria da Aprendizagem Significativa e a aprendizagem atitudinal, pois, para que um indivíduo aprenda ou mude uma atitude, ele precisa avaliar, elaborar (ou reelaborar) suas condutas a partir da reflexão sobre os modos de agir que ele, ou pessoas próximas a ele, mantêm. A consistência e a consciência atitudinal estão sujeitas a um processo de reflexão e interiorização sobre normas e valores já conhecidos e/ou vivenciados pelo aprendiz (SARABIA, 1998). Nesse 
sentido, tanto a reflexão quanto a interiorização de normas e valores que se pretende ensinar aos alunos dependem de o conteúdo atitudinal ser substantivo e não arbitrário (AUSUBEL, 1963) para eles.

O mapa conceitual a seguir organiza resumidamente as conexões que podem ser estabelecidas entre os eixos teóricos aqui expostos.

Figura 4 - Conexões entre a Teoria da Aprendizagem Significativa e os Conteúdos de Aprendizagem

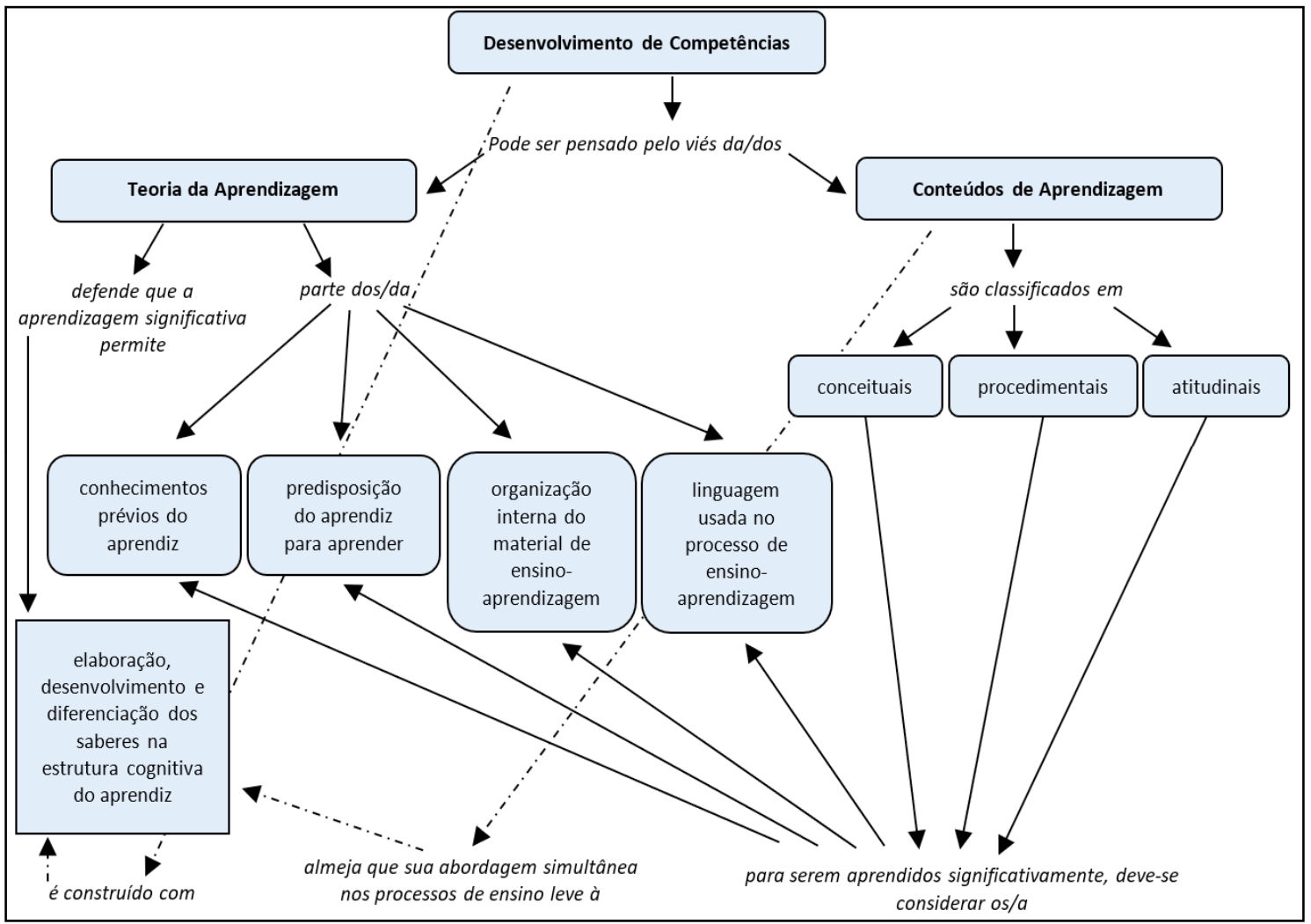

Fonte: Os autores.

De acordo com o mapa conceitual que desenhamos (Figura 4), as estratégias educacionais que visam, entre outros, ao desenvolvimento de competências nos alunos, podem ser planejadas a partir do atrelamento colateral entre os pressupostos da Teoria da Aprendizagem Significativa e das considerações acerca das diferentes naturezas dos Conteúdos de Aprendizagem.

Em nosso entendimento, a construção de aprendizagens significativas que levam à estabilidade dos saberes nas mentes dos aprendizes é compatível com a abordagem simultânea dos diferentes conteúdos de aprendizagem que formam os materiais a serem ensinados e aprendidos, pois conduzem à elaboração, ao desenvolvimento e à diferenciação dos conhecimentos. Para que isso ocorra efetivamente, defendemos que o trabalho nas situações de ensino deva partir da articulação dos conhecimentos prévios conceituais, procedimentais e atitudinais que os alunos carregam consigo e considerar a relevância que o material de ensino tem para o aprendiz, a organização interna deste material, bem como as linguagens com que são ministrados. 


\section{CONSIDERAÇÕES FINAIS}

Diante do contexto educacional que tem reconsiderado os currículos escolares, para que eles, de fato, proporcionem aos aprendizes o desenvolvimento de competências conceituais, procedimentais e atitudinais em suas formações, nosso estudo buscou pensar alternativas para o cumprimento de tais objetivos, propondo uma leitura das conexões entre os pressupostos da Teoria da Aprendizagem Significativa e do modelo teórico dos Conteúdos de Aprendizagem.

Como proposta, imaginamos a Aprendizagem Significativa para além de conceitos, acontecendo de forma conjunta à de procedimentos e atitudes. Tal compreensão é relevante quando se almeja a formação de cidadãos que assumam posições com respeito ao uso social dos saberes escolares, pois ela torna os aprendizes aptos a relacionar conhecimentos científicos, mudança social, opiniões ideológicas e hábitos de conduta.

Finalizando nossa explanação, aspiramos que as colocações aqui apresentadas colaborem para o avanço das discussões que são feitas entre pesquisadores da área de ensino e aprendizagem, e reconhecemos que há campo para o avanço nas investigações que atrelam os referenciais teóricos aqui abordados.

\section{REFERÊNCIAS}

ALONSO TAPIA, J. Motivar para el aprendizaje. Barcelona: Edebé, 1997.

AUSUBEL, D. P. Aquisição e retenção de conhecimentos. Lisboa: Plátano Edições Técnicas, 2003. (Original: The acquisition and retention of knowledge. Dordrecht: Kluwer Academic Publishers, 2000).

AUSUBEL, D. P. The psychology of meaningful verbal learning. Nova York: Grune and Stratton, 1963.

AUSUBEL, D. P.; NOVAK, J. D.; HANESIAN, H. Psicologia educacional. Tradução Eva Nick et al. Rio de Janeiro: Interamericana, 1980. (Original: Educational Psychology: a cognitive view. New York: Holt, Rinehart and Winston, 1978).

BRASIL. Ministério da Educação. Base nacional comum curricular: educação é a base. Brasília, 2017. Disponível em: http://basenacionalcomum.mec.gov.br/abase. Acesso em: 10 jun. 2018.

BRASIL. Ministério da Educação. Diretrizes curriculares nacionais da educação básica. Brasília, 2013. Disponível em: http://portal.mec.gov.br/index.php?option=com_docman\&view=download\&alias=13448-diretrizes-curiculares-nacionais-2013-pdf\&Itemid=30192. Acesso em: 1o jun. 2018.BRASIL. Ministério da Educação. Lei n. 9.394 de 17 de dezembro de 1996. Diretrizes e Bases da Educação Nacional. Brasília: DOU, 23 dez. 1996. Disponível em: http://www.planalto.gov.br/ccivil_03/Leis/L9394.htm. Acesso em: 1으 jun. 2018.

CLAXTON, G. Live and learn. Londres: Harper \& Row, 1984.

COLL, C.; POZO, J. I.; SARABIA, B.; WALLS, E. Os conteúdos na reforma: ensino e aprendizagem de conceitos, procedimentos e atitudes. Tradução Beatriz Affonso Neves. Porto Alegre: Artmed, 1998.

COLL, C.; VALLS, E. A aprendizagem e o ensino dos procedimentos. In: COLL, C. et al. Os conteúdos na reforma: ensino e aprendizagem de conceitos, procedimentos e atitudes. Tradução Beatriz Affonso Neves. Porto Alegre: Artmed, 1998. p. 73-118.

EL-HANI, C. N.; MORTIMER, E. F. Multicultural education, pragmatism, and the goals of science teaching. Cultural Studies of Science Education, Berlin: Springer, n. 2, p. 657-702, set. 2007.

FRASSON, F. Aprendizagem significativa conceitual, procedimental e atitudinal na educação alimentar e nutricional, no Ensino Fundamental, por meio de multiplicidade representacional. 2016. Dissertação (Mestrado em Ensino de Ciências) - Universidade Estadual de Londrina, Londrina, 2016.

GARDNER, H. Inteligências múltiplas, a teoria na prática. Porto Alegre: Artmed, 1995.

HERNANDES, J. L. Relações sintagmáticas e paradigmáticas para apropriação de conceitos de termoquímica. 2018. Dissertação (Mestrado em Ensino de Ciencias) - Universidade Estadual de Londrina, Londrina, 2018.HUERTAS, J. A. Motivación. Querer aprender. Buenos Aires: Aique, 1997. 
KLEIN, T. A. S.; LABURÚ, C. E. Multimodos de representação e Teoria da Aprendizagem Significativa: possíveis interconexões na construção do conceito de biotecnologia. Revista Ensaio, Belo Horizonte, v. 14, n. 2, p. 137-152, ago./nov. 2012.

LABURÚ, C. E.; CARVALHO, M. Educação científica: controvérsias construtivistas e pluralismo metodológico. Londrina: Eduel, 2005.

LABURÚ, C. E.; SILVA, O. H. M. da. Multimodos e múltiplas representações: fundamentos e perspectivas semióticas para a aprendizagem de conceitos científicos. Investigações em Ensino de Ciências (online), v. 16, p. 7-33, 2011. Disponível em: https://www.if.ufrgs.br/cref/ojs/index.php/ienci/article/view/244/170.

LABURÚ, C. E.; ZOMPERO, A. F.; BARROS, M. A. Vygotsky e múltiplas representações: leituras convergentes para o ensino de ciências. Caderno Brasileiro de Ensino de Física, Florianópolis, v. 30, n. 1, p. 7-24, abr. 2013.

MELENDÉZ, A. Z. Los contenidos procedimentales en el proceso de enseñanza-aprendizaje. 2012. Tese (Doutorado em Ensino de Ciências) - Universidad de Granada, Granada, 2012.

MOREIRA, M. A. ¿Al final, qué es aprendizaje significativo? Revista Qurriculum, n. 25, p. 29-56, 2012. Disponível em: https://qurriculum.webs.ull.es/?p=716. Acesso em: 4 jun. 2018.MOREIRA, M. A. A teoria da aprendizagem significativa e sua implementação em sala de aula. Brasília: UnB, 2006.

MOREIRA, M. A. Aprendizagem significativa. São Paulo: LF, 2011.

MOREIRA, M. A. Teorias de aprendizagem. 2. ed. São Paulo: EPU, 2014.

MOREIRA, M. A.; MASINI, E. A. F. S. Aprendizagem significativa: a teoria de David Ausubel. São Paulo: Moraes, 1982.

MOSCOVICI, S.; MUGNY, G.; PÉREZ, J. A. La influencia social inconsciente. Barcelona: Anthropos, 1991.

NARDY M.; LABURÚ, C. E. Aprendizagem significativa e educação ambiental: um possível diálogo a partir de estratégias multimodais. Aprendizagem Significativa em Revista, Porto Alegre, v. 4, n. 3, p. 26-36, dez. 2014.

PERUCCI, L. R. Eixos estruturantes da linguagem e as paráfrases para a apropriação de conceitos de matéria e energia nos ecossistemas. 2015. Dissertação (Mestrado em Ensino de Ciências) - Universidade Estadual de Londrina, Londrina, 2015.POZO, J. I. A aprendizagem e o ensino de fatos e conceitos. In: COLL, C. et al. Os conteúdos na reforma: ensino e aprendizagem de conceitos, procedimentos e atitudes. Tradução Beatriz Affonso Neves. Porto Alegre: Artmed, 1998. p. 19-71.

POZO, J. I.; GÓMEZ CRESPO, M. A. A aprendizagem e o ensino de ciências: do conhecimento cotidiano ao conhecimento científico. 5. ed. Porto Alegre: Artmed, 2009.

RAMAL, A. Sair do conteudismo para as competências é o maior desafio da BNCC. Globo.com. São Paulo, 2017. Disponível em: http://g1.globo.com/educacao/blog/andrea-ramal/post/sair-do-conteudismo-para-competencias-e-o-maior-desafio-da-bncc.html. Acesso em: 25 out. 2018.

SANTOS, Leonor. A articulação entre a avaliação somativa e a formativa, na prática pedagógica: uma impossibilidade ou um desafio? Ensaio, Rio de Janeiro, v. 24, n. 92, p. 637-669, jul./set. 2016.

SARABIA, B. A aprendizagem e o ensino das atitudes. In: COLL, C. et al. Os conteúdos na reforma: ensino e aprendizagem de conceitos, procedimentos e atitudes. Tradução Beatriz Affonso Neves. Porto Alegre: Artmed, 1998. p. 119-178.

ZABALA, A. A prática educativa: como ensinar. Tradução Ernani Rosa. 2. ed. Porto Alegre: Artmed, 1998. ZABALA, A. Como trabalhar os conteúdos procedimentais em aula. Tradução Ernani Rosa. 2. ed. Porto Alegre: Artmed, 1999. 